\title{
A Small Step for Obesity but a Great Leap in the Wrong Direction for Mankind
}

\author{
Neville J. Rigby ${ }^{\mathrm{a}} \quad$ Manfred J. Müller ${ }^{\mathrm{b}}$ \\ a European policy adviser to the Obesity Forum, Neville Rigby and Associates, London, UK \\ ${ }^{\mathrm{b}}$ Institute of Human Nutrition and Food Science, Christian-Albrechts-University Kiel, Kiel, Germany
}

Recently, the Joint Task Force of the American Society for Nutrition (ASN), Institute of Food Technologists, and International Food Information Council, proposed the de-facto globalisation of a 'small changes' approach to address the worldwide problem of obesity [1]. The basis of their argument was that 'obesity rates are increasing because of a gradual weight gain in most populations,' existing attempts to address obesity through so-called lifestyle changes have not succeeded, therefore for the present the alternative should be to focus not on achieving weight loss, but on promoting small changes in diet and physical activity to prevent further weight gain. By adopting this strategy, the Task Force argued, obesity rates would be 'stabilised' and over time decrease gradually.

In attempting to define what is meant by small changes, Hill et al. [2] have suggested that minimal measures such as 2,000 more steps per day walking, expending only $100 \mathrm{kcal}$ or substituting diet soda for a regular soda, which would eliminate $150 \mathrm{kcal}$ per 340.2-g serving, might offer a 'more sustainable' strategy than the greater efforts necessary for permanent weight-loss maintenance. The problem is more complicated in children for whom a small energy surplus is necessary for growth. Preventing overweight in growing children may involve limiting this energy surplus to 46-72 $\mathrm{kcal} /$ day [3]. It would be a bold claim for even seasoned nutritionists to suggest they could monitor their personal energy equilibrium with such accuracy.

Yet, the Task Force proposal suggests: 'Small changes in diet and/or in physical activity, which might still fall short of optimal diet and physical activity recommendations, might be sufficient to stop the gradual weight gain of individuals and populations.' Apart from some sweeping assumptions about the likely effectiveness of small changes, if taken seriously, this approach would necessitate the acceptance of an already high prevalence of obesity, not merely in the USA but worldwide, as a new 'stabilised' norm with all its consequences in terms of co-morbidities. With little or no evidence available to date to show how effective the 'easy option' approach might turn out to be in the USA, it seems somewhat premature, if not more than a little audacious, to suggest that the rest of the world - already committed in principle to the WHO global strategy on diet, physical activity and health [4] - should relax and adopt the highly speculative strategy of accepting that things continue as they are while relying on just a few little changes in the hope of avoiding further worsening in the situation.

There are many factors influencing both population mean weight gain and obesity. First documented more than half a century ago, the migration of rural populations to the cities of South Africa prompted concerns about the adverse impact on health of the urban diet, and for several decades, the black African female population of the Cape Town region has suffered an obesity prevalence comparable to that in the USA [5]. In China, overweight and obesity affects 260 million adults [6], in Russia 1 in 5 women is obese [7], and in selected Middle East countries, overweight and obesity rank highest in occupied Palestine with $59 \%$ of men and $71 \%$ of women affected [8] - indicative of an aetiology more complex than merely marginal 'lifestyle' choices, and a reminder that obesity and under-nutrition often co-exist in the same environments. With rising childhood obesity rates now setting a consistently higher baseline, adult obesity rates are already edging towards US levels in some countries.

Obesity is associated with a marked range of socio-economic inequalities, particularly amongst women; in the USA this is hardly a new phenomenon [9]. In 1965, a large study found a 6-fold variation in obesity between lowest and highest SES (socio-economic status) category females in Midtown Manhattan, with a prevalence of $37 \%$ in the very lowest SES [10]. The same study revealed an obesity prevalence of $32 \%$ among lower SES males - twice the level of the upper SES group. More recently, progressive inverse gradients reflecting the association between socio-economic conditions and health including overweight have been identified among children [11]. Thus it is important to remember that obesity, as Sir Michael Marmot notes, 'goes to the heart of the way we live as

\section{KARGER}

Fax +497614520714

Information@Karger.de

www.karger.com (c) 2009 S. Karger GmbH, Freiburg

Accessible online at:

www.karger.com/ofa
Dr. Neville James Rigby

(formerly Director of Policy and Public Affairs, IASO)

Neville Rigby \& Associates

4 Moreton Place, London SW1V 2NP, UK

Tel. +44 2079766447

nevillerigby@aol.com 
individuals and how we organise our affairs as societies' [12]. Any serious solution to the overweight problem must also address these deep-rooted relationships between SES and health (i.e. the cause of the causes). Far bigger and bolder steps are required.

Long-term consumption patterns in the developed and developing countries provide clear evidence that despite the chronic failure to address under-nutrition, for most of the world's population energy intake has risen and continues to do so, whilst the need and opportunity for physical activity has diminished [13]. There seems little likelihood - even in an era of concern about food security - that this will change dramatically. The importance of a more fundamental reassessment of food quality - as envisaged in the WHO global strategy on diet and physical activity - thus becomes imperative.

The industrialised global food sector is well aware of the need to make major changes, but so far has remained quite selective about what changes - large or small - it is ready to implement. Whilst minor modifications engineered by food technologists have allowed marketing advantages associated with claims of 'reduced fat' even in biscuits, crisps and a range of prepared food niche products, and whilst food industry funded advocacy groups continue to promulgate the innuendo that anything goes 'as part of a balanced diet', the challenge to improve overall nutritional quality - a factor which itself could transform the obesogenic food environment - has still to be taken seriously.

In practice, it is not merely what the food sector manufactures, but the way in which a very selective product range is marketed that needs to be addressed with greater responsibility. Children remain easy targets, but everyone is affected, with Asian populations most vulnerable to the damaging effects of 'western' diets. Inviting them to adopt small changes whilst facing the novel barrage of western marketing techniques could be regarded as cynical. In reality, the suggestion that the rest of the world might opt for the ASN Task Force's minimal changes approach risks undermining the progress achieved to date, and the increasing pressure worldwide for action on marketing to children. A working group of the International Obesity Task Force (IOTF) specified a framework, the Sydney Principles, within which measures to protect children from overexposure to marketing of food and beverages of minimal nutritional value [14]. A further set of recommendations for a draft code on marketing to children has been prepared jointly by the IOTF and Consumers International [15]. While the limited protection afforded in law in Quebec and Sweden has been circumvented by cross-border advertising specifically targeting children, and more recent attempts to introduce advertising restrictions in the UK failed to halt peak-time advertising influencing children, marketing efforts are now sharply focused on the use of the Internet, which provides a powerful tool to reach children in all parts of the world. Voluntary commitments from commercial coalitions have remained to date effectively statements of the status-quo agreements - small steps rather than large strides towards better protection for children.

As the WHO Commission on the Social Determinants of Health noted [16], 'a significant challenge remains: to engage with the multiple sectors outside health in areas such as trade, agriculture, employment, and education, areas in which action must take place if we are to redress the global obesity epidemic.' Despite this challenge, even now the purveyors of high-calorie low nutritional value fast foods see a silver lining in the financial storm clouds overshadowing most of the world's economies, and are gearing for continued expansion in the fast developing economies like China. In this context, emphasizing the individual minor changes as a way forward seems to offer little more than a smokescreen to hide (the major changes that are needed. Perhaps the irony should not be entirely lost on Americans, living down their reputation for claiming that everything in the USA was bigger and better. Settling for small steps, rather than significant strategies to counteract obesity, can only guarantee that the problem will get bigger and worse. The world cannot afford to follow suit.

\section{References}

1 Hill JO: Can a small-changes approach help address the obesity epidemic? A report of the Joint Task Force of the American Society for Nutrition, Institute of Food Technologists, and International Food Information Council. Am J Clin Nutr 2009;89:477-484.

2 Hill JO, Wyatt HR, Reed GW, Peters JC: Obesity and the environment: where do we go from here? Science 2003;299:853-855.

3 Plachta-Danielzik S, Landsberg B, Bosy-Westphal A, et al: Energy gain and energy gap in normalweight children: Longitudinal data of the KOPS. Obesity 2008;16:777-783

4 Fifty-seventh World Health Assembly: WHA57.17: Global strategy on diet, physical activity and health, adopted May 2004. www.who.int/gb/ebwha/ pdf_files/WHA57/A57_R17-en.pdf.

5 Walker ARP, Adam F, Walker BF: World pandemic of obesity: The situation in Southern African populations. Public Health 2001;115:368-372.
6 Wu Y: Overweight and obesity in China (Editorial). BMJ 2006;333;362-363.

7 Jahns L, Baturin A, Popkin BM: Obesity, diet, and poverty: trends in the Russian transition to market economy. Eur J Clin Nutr 2003;57:1295-1302.

8 Husseini A, Abu-Rmeileh NME, Mikki N, et al: Cardiovascular diseases, diabetes mellitus, and cancer in the occupied Palestinian territory. Lancet 2009;373: 1041-1049.

9 Sobal J, Stunkard AJ: Socioeconomic status and obesity: A review of the literature. Psychol Bull 1989;105:260-275.

10 Goldblatt PB, Moore ME, Stunkard AJ: Social factors in obesity. JAMA 1965;192:1039-1044.

11 Müller MJ, Danielzik S: Childhood overweight: Is there need for a new societal approach to the obesity epidemic. Obes Rev 2006;8:87-90.

12 Marmot M: Status Syndrome. London, Bloomsbury, 2004.
3 Schmidhuber J, Shetty P: The nutrition transition to 2030. Why developing countries are likely to bear the major burden. Acta Agriculturae Scand Section C 2005;2(3-4):150-166.

14 Swinburn B et al as the International Obesity Taskforce Working Group on Marketing to Children: Sydney Principles' for reducing the commercial promotion of foods and beverages to children. Public Health Nutr 2008;11:881-886.

15 International Obesity Task Force (ed): Recommendations for an International Code on Marketing of Foods and Non-Alcoholic Beverages to Children. www.consumersinternational.org/shared_asp_files/ GFSR.asp? NodeID=97478.

16 World Health Organization (ed): Closing the gap in a generation: health equity through action on the social determinants of health. Final Report of the Commission on Social Determinants of Health. Geneva, World Health Organization, 2008. http://whqlibdoc.who.int/publications/2008/9789241563703_eng.pdf. 


\section{On the Contents of This Issue}

We are all aware of the fact that the BMI is a rather crude predictor of cardiovascular disease (CVD) risk factors. In 1946, Jean Vague found differences in health risk according to the central and peripheral type of fat distribution. Subsequently, the waist-to-hip ratio and waist circumference were used to assess health risks. The latest achievement has been to employ the waist-to-height ratio (WHtR). Ashwell and Gibson (United Kingdom) [1] again provide compelling support for the use of this ratio: Amongst almost 1,800 adult individuals representative of the British population, the WHtR was more strongly associated with CVD risk factors than the BMI. The WHtR not only predicted these risk factors in overweight individuals, but also in those with a normal BMI. Based on the current and other studies, the recommendation is to keep your waist circumference to less than half your height (WHtR $<0.5$ ).

Mauriège (Canada) et al. [2] examined the effects of a short-term weight reduction programme particularly on eating behaviours in 44 females with class-I obesity and 39 females with a BMI $\geq 35 \mathrm{~kg} / \mathrm{m}^{2}$. Based on the Three-Factor Eating Questionnaire, the more obese group was found to have a higher flexible restriction after the 3-week programme. Based on their findings, the authors argue that behavioural interventions specifically designed to increase flexible and to decrease rigid restriction scores are more warranted in females with a BMI $<35 \mathrm{~kg} / \mathrm{m}^{2}$.

Are children and adolescents with obesity at an increased risk of psychiatric disorders? The current literature suggests that population-based young obese individuals do not have a substantially increased risk; in contrast, subjects seeking treatment have been shown to have elevated rates of both mood and anxiety disorders. Eschenbeck et al. (Germany) [3] had the unique opportunity to analyse data of a German national health insurance company including 156,948 children aged 6-14 years. Physician-diagnosed obesity resulted in higher odds ratios for externalising $(\mathrm{OR}=1.64)$ and internalising disorders $(\mathrm{OR}=2.0)$, sleep disorders (OR $=1.87)$, and a stay in hospital $(\mathrm{OR}=1.44)$. Further analyses revealed that girls are at an elevated risk for both externalising and internalising disorders compared to boys; older subjects with physician-diagnosed obesity had higher risks for internalising disorders than the younger individuals with obesity. A sub-differentiation of externalising disorders revealed that a higher odds ratio was associated with conduct disorders more than with hyperkinetic disorders. Anxiety disorders were associated with higher odds ratios across all age groups than for depressive disorders. A possible explanation for these observations is a confounding factor due to socio-economic status (SES), which was unfortunately not co-determined. Thus, children of a lower SES could have elevated rates for obesity, externalising and internalising disorders. Despite this limitation, the large sample size and the robust findings of associations between physician-diagnosed obesity and the respective disorders convincingly underscore the respective associations.

What if you have a child or adolescent with an externalising disorder in your weight-loss programme? Such a child with disruptive behaviour is bound to annoy both other children within the programme and the supervisor. Kirschenbaum et al. (United States) [4] were successful in identifying such individuals prior to admission to a largescale immersion programme for the treatment of adolescent obesity. Those campers whose enrolment forms revealed evidence of a history of psychological distress, major medical challenges, and/or developmental delays were subjected to a screening procedure by a licensed psychologist who after talking with the respective applicant, parents, and health care providers determined whether or not to admit the child to the camp. Out of the total of 554 overweight young people (mean age: 15.8 years, mean BMI: $\left.35.6 \mathrm{~kg} / \mathrm{m}^{2}\right), 8.7 \%$ were 'red-flagged'. During summer 2007 , $8 \%$ of the campers were dismissed prematurely. The redflagging procedure was successful: $30 \%$ of the red-flagged individuals admitted to the camp were dismissed prematurely in contrast to only $6.6 \%$ of the non-flagged campers. If children with disruptive behaviours cause problems within your weight-loss reduction programme, this article will prove valuable to you. Obviously, those obese young individuals with co-morbid externalising disorders pose a significant challenge for weight reduction programmes.

Internet-based treatment programmes are on the advance. But do they serve older as well as younger individuals? Van der Mark et al. (Sweden) [5] analysed data on 4,440 active participants accessing the Internet-based weight club during a 6-month period. The number of logins, food intake, and weight records were examined. Interestingly, subjects aged $\geq 65$ years were more likely to remain active in the weight club than younger subjects. Woman aged $\geq 65$ years had the highest mean percentage of weight loss equivalent to $5.6 \mathrm{~kg}$. Men $\geq 65$ years had the highest number of log-ins (mean $=161)$. The authors discuss potential limitations of the study including a selection bias for the willingness of the weight club members to participate in the scientific study. Approximately $40 \%$ of the study participants had more than 12 years of education as compared to $30 \%$ of the Swedish population. This rate could have been even higher among the comparatively small group of individuals $\geq 65$ years, thus potentially partially accounting for the respective findings.

Why is measured weight loss frequently less than that predicted at a given energy deficit? Usually, this difference is attributed to poor patient compliance. Goele et al. 
(Germany) [6] analysed the extent to which adaptive thermogenesis contributes to the difference between measured and predicted weight loss. For this purpose, 48 overweight and obese female patients (mean BMI $35.4 \pm 4.4 \mathrm{~kg} / \mathrm{m}^{2}$ ) were investigated before and 14 weeks after dietary treatment with 1,000 kcal/day. Measured weight loss proved to be only $44 \%$ of the predicted value. $14 \%$ of the difference between measured and predicted weight loss was explained by the higher proportion of fat mass in weight loss and $38 \%$ by adaptive thermogenesis. Accordingly, poor compliance was held responsible for only roughly $50 \%$ of the difference between measured and predicted weight loss.

Many G-protein-coupled receptors (GPCR) are expressed in hypothalamic regions. Both hetero- and homodimerisation of GPCR have been reported. Homo- or heterodimerisation could potentially influence trafficking to the cell surface, ligand binding, G-protein-coupling, and agonist-induced internalisation. Rediger and co-workers (Germany) [7] investigated the interaction of both melanocortin-3 and -4 receptors with other GPCRs potentially expressed in the hypothalamus and known to be involved in weight regulation. A number of such GPCRs were cloned into an eukaryotic expression vector. Cell surface expression was demonstrated by an ELISA approach, sub-cellular distribution was investigated by confocal laser microscopy. A sandwich ELISA and fluorescence resonance energy transfer (FRET) were used to determine protein-protein interaction. A robust interaction of the MC4R with GPR7 and a strong interaction of the MC3R with the growth hormone secretagogue receptor were identified. The investigators conclude that heterodimerisation presumably contributes to the complexity of weight regulation. Furthermore, such knowledge might be helpful for developing novel pharmacological treatments of obesity.

Neurotransmitters, neuropeptides and hormones commonly come into mind when we think about the hypothalamus and its role in the control of energy homoeostasis. Diéguez et al. (Spain) [8] highlight the modulation of hypothalamic lipid metabolism and its critical role in feeding control. They show that peripheral hormonal and nutrient/metabolic signals operate on the different components of the fatty acid metabolic pathway, thus modulating the cytoplasmatic pool of malonyl-CoA and palmitoyl-CoA.
This in turn leads to changes in expression of anorexigenic and orexigenic neuropeptides. The insight into the important role of the fatty acid metabolic pathway will potentially allow identification and validation of novel targets for obesity drugs.

In a second review, Hall et al. (United Kingdom) [9] discuss the physiology of the hormones leptin, adiponectin, resistin, peptide YY, and ghrelin. The role of each of these hormones in energy homoeostasis, weight regulation, and the pathogenesis of obesity and insulin resistance is highlighted. The respective hormones are attributed to either long- or short-term control of energy homoeostasis. The authors summarise the current knowledge pertaining to pharmacological interventions via the respective pathways and conclude that the clinical applications for these hormones currently remain limited. However, they argue that further research into adipokines and gut hormones could offer valuable therapeutic approaches to both obesity and comorbid disorders.

Johannes Hebebrand, Essen

\section{References}

1 Ashwell M, Gibson S: Waist to height ratio is a simple and effective obesity screening tool for cardiovascular risk factors: analysis of data from the British national diet and nutrition survey of adults aged 19-64 years. Obes Facts 2009;2(2):97-103.

2 Riesco E, Rossel N, Rusques C, Mirepoix M, Drapeau V, Sanguignol V, Mauriège P: Impact of weight reduction on eating behaviors and quality of life: influence of the obesity degree. Obes Facts 2009;2(2):87-95.

3 Eschenbeck H, Kohlmann C-W, Dudey S, Schürholz T: Physician-diagnosed obesity in 156,948 German 6- to 14-year-olds. Prevalence and comorbidity of internalising disorders, externalising disorders, and sleep disorders. Obes Facts 2009;2(2):67-73.

4 Kirschenbaum DS, Kelly KP, Germann JN: Efficacy of a screening procedure to identify potentially disruptive participants in an immersion program for the treatment of adolescent obesity. Obes Facts 2009;2(2):110-115.

5 van der Mark M, Jonasson J, Svensson M, Linné Y, Rössner S, Trolle Lagerros L: Older members perform better in an Internet-based behavioral weight loss program compared to younger members. Obes Facts 2009;2(2):74-79.

6 Goele K, Bosy-Westphal A, Rümcker B, Lagerpusch M, Müller MJ: Influence of changes in body composition and adaptive thermogenesis on the difference between measured and predicted weight loss in obese women. Obes Facts 2009;2(2):105-109.

7 Rediger A, Tarnow P, Bickenbach A, Schaefer M, Krude H, Grüters A, Biebermann H: Heterodimerization of hypothalamic g-protein-coupled receptors involved in weight regulation. Obes Facts 2009;2(2):80-86.

8 Diéguez C, Frühbeck G, López M: Hypothalamic lipids and the regulation of energy homoeostasis. Obes Facts 2009;2(2):126-135.

9 Hall J, Roberts R, Vora N: Energy homoeostasis: the roles of adipose tissuederived hormones, peptide yy and ghrelin. Obes Facts 2009;2(2):117-125. 